\title{
Sliding Mode Control of Induction Motor with Vector Control in Field Weakening
}

\author{
Ziad Hussein Salih ${ }^{1}$, Khalaf S. Gaeid ${ }^{2} \&$ Ali Saghafinia ${ }^{3}$ \\ ${ }^{1}$ Petroleum and Mineral Engineering Faculty, Tikrit University, Iraq \\ ${ }^{2}$ Engineering Faculty, Tikrit University, Iraq \\ ${ }^{3}$ UMPEDAC center, University of Malaya, Malaysia
}

Correspondence: Ziad Hussein Salih, Petroleum and Mineral Engineering Faculty, Tikrit University, Iraq. Tel: 964-770-305-7076. E-mail: gaeidkhalaf@gmail.com

Received: September 5, 2014

doi:10.5539/mas.v9n2p276
Accepted: September 23, $2014 \quad$ Online Published: January 28, 2015

URL: http://dx.doi.org/10.5539/mas.v9n2p276

\begin{abstract}
This paper presents a vector control sliding mode control (SMC) scheme in the field weakening (FW) region with optimal flux based algorithm. The observation of the rotor flux and stator flux components are also included. This work proves the advantages of vector controlled IM for high performance application in the industry. The vector control ability for easy FW and full voltage and current utilization of inverter fed IM to ensure a wide range of sufficient speed and torque operation was investigated in this work. In a sensorless vector controlled IM, the speed must be estimated using voltage and current components. The parameter variations is the main problem in the high speed operation of IM so that, the sensorless speed estimation through SM technique in the FW region with optimal flux measurement is presented. Space vector pulse width modulation (SVPWM) voltage source inverter is utilized in the algorithm. The simulation results shows the effectiveness of this algorithm at all speed range of operation.
\end{abstract}

Keywords: field weakening, expanded control techniques, sliding mode observer, optimal flux, vector control

\section{Introduction}

The induction motors (IM) plays an important role in the industry due to their low cost and operational reliability. The percentage of the squirrel cage IM in the industry can be illustrated in Figure 1.

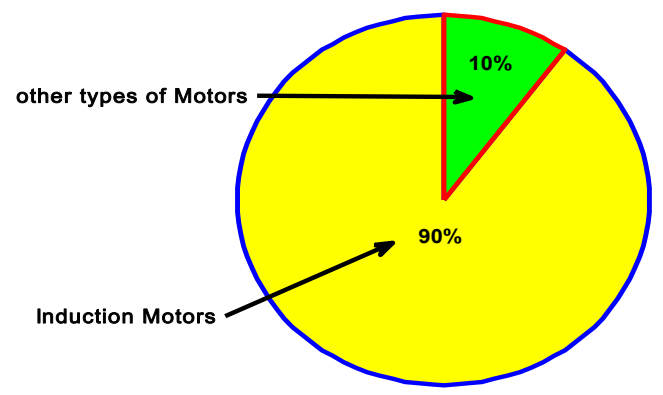

Figure 1. Squirrel cage induction motor percentage in the industry

Speed estimation of the machines can be applied in applications where the speed sensor can be damaged has been done by (Grzegorz Tarchala et al., 2013). Three parameters should be obtained to complete sensorless control algorithm, i.e. stator flux vector, motor torque and reference speed. These parameters can be estimated using different control techniques such as sliding mode observer(SMO) (Z. Yan et al.,2000), Model Reference Adaptive System (MRAS) estimators as in (Khalaf Salloum Gaeid et al.,2012)\& (Dafang Wang et al.,2013), Kalman filters( Boyu Yi et al.,2013), neural network(Kusuma Gottapu et al.,2013).

The expanded control techniques of IM control is shown in Figure2.

Sensorless algorithm reduces the cost of the motor drive, increases both the reliability and noise immunity with 
low maintenance of the given system (Mateusz Dybkowski et al., 2013) \& (ArafaS.Mohamed et al., 2011). Additional cable reduction can be assured by sensorless.

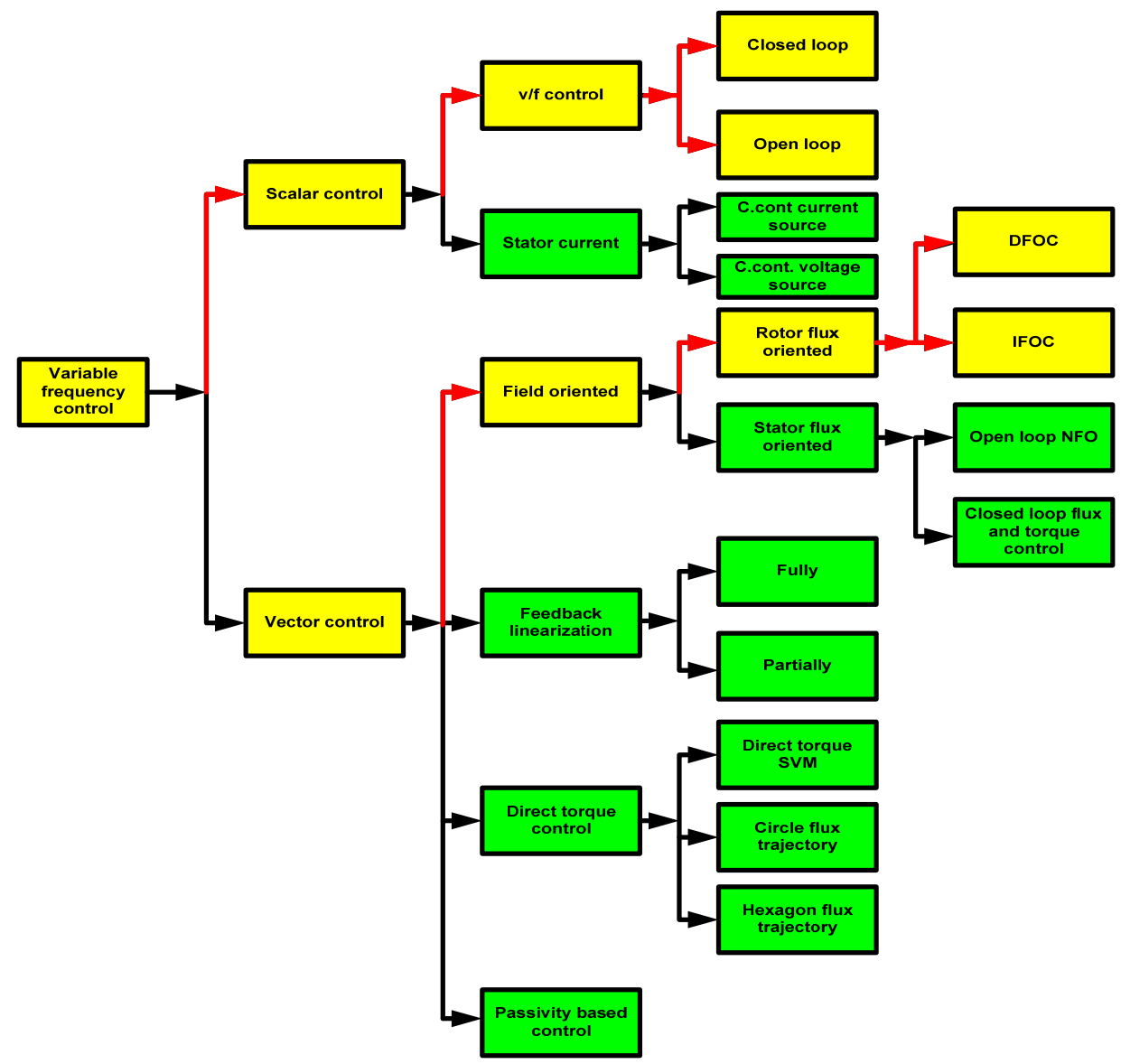

Figure 2. Expanded control techniques of IM control

Best performance of the drives can be obtained by one of the field oriented control (FOC) methods either the direct or indirect to obtain a robust solutions for IM. The IM operation can be divided into three speed ranges, constant torque, constant power speed and constant slip frequency (D. Casadei et al. 2006).

In the first region (constant torque), the actual speed cannot be reached to the rated speed level. Hence speed steady state error is exists.

In the second region (constant power speed), the frequency of the IM increases and the supplied power to the load decreases proportionally with the rotor speed. In the third region (constant slip frequency), the torque and mechanical speed relationship as .

Where $\omega_{m}^{2}$ is the squared mechanical speed

$$
T_{e} \propto \frac{1}{\omega_{m}^{2}}
$$

Operation in the field weakening (FW) region which is above the IM reference speed achieves and compromises of high speed and high torque. In the FW region, the torque can be increased to its maximum level by adjusting the magnetic field. The rotor speed is inversely proportion to the stator flux as well as the rotor flux is getting reduced to below its rated value due to increasing of the actual speed more than the reference speed.

A lot of researches has been reported and suggested various approaches in order to achieve this goal such as (P. Y. Lin \& Y. S. Lai, 2011).

Sensorless vector control scheme based on speed estimation algorithm with an integral sliding mode observer to compensate the system uncertainties presented in (Sobha Chandra Bbarik,2007). Speed estimation based on (SMO), which combines variable structure control(VSS), Popov's hyper stability theory is presented by (G. Venkatesh ,2013). The rotor flux based model reference adaptive system (MRAS) presented by (P. Vas, 1992) is 
one of the most popular methods for the flux and speed estimations. The error is calculated using voltage and current models of the rotor flux and speed.

SMO based rotor flux estimation scheme for sensorless field oriented control (FOC) is developed to track the stator currents and the control signals of the observer presented in (Yong Feng et al., 2012).

Speed estimation from the output of the PI controller operated by the flux error signal in closed loop system is presented by (C. Kamal Basha et al., 2013).

The SMC based motor drive system has many features such as, it is robust to parameter variations, the model uncertainties are insensitive to external load disturbances, fast dynamic response, stable control system, it can handle some nonlinear systems that are not stable by using a linear controller (Ali Saghafinia et al., 2013).

The main objective of this paper are to combine the sensorless vector controlled IM in FW region with SMO and optimal flux measurements such that the machine can be precisely used in a wide range of operation.

The paper is organized as follows. Section II provides modeling of IM. Section III presents the FW control of IM. Section IV explains SVPWM technique. Section V presents sliding mode observer. Section VI introduces the simulation results and Section VII presents the main conclusions of this work.

\section{Modeling of IM}

Vector control decouples flux and torque currents so as to linearly control the output torque of a nonlinear IM. The 3- $\varphi$ of voltage and current are transformed into 2- $\varphi$ d-q axes. The d-q frame rotates synchronously with the rotor flux space vector (Gaeid, Khalaf Salloum et al., 2012). Independent control of motor flux and torque can be obtained by this method. Figure 3 shows the vector diagram of IM in stationary $\alpha-\beta$ and rotating $d-q$ coordinates.

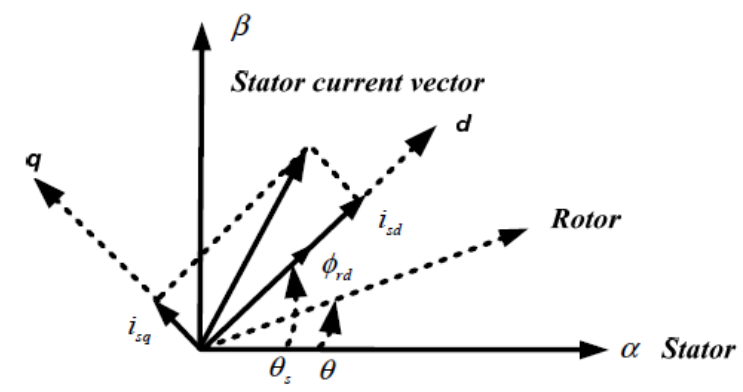

Figure 3. Stationary reference frame for vector control (Gaeid, Khalaf Salloum et al., 2012)

Modeling of the IM is essential for the SMO design. The model of the squirrel cage IM can be derived using the commonly known assumptions (The magnetic field intensity is constant, 3- $\varphi$ symmetry, no saliency effects, magnetizing linearity) in a stationary reference frame $\alpha-\beta$ (Grzegorz Tarchala et al. 2013).

1. IM voltage equations:

$$
\begin{aligned}
& v_{s}=r_{s} i_{s}+T_{s} \frac{d \psi_{s}}{d t} \\
& 0=r_{r} i_{r}+T_{s} \frac{d \psi_{r}}{d t}-j \omega_{m} \psi_{r}
\end{aligned}
$$

Where $v_{s}, i_{s}$ is the space vectors of the stator voltage and current respectively, its values are

$$
\begin{aligned}
& v_{s}=v_{s \alpha}+j v_{s \beta} \\
& i_{s}=i_{s \alpha}+j i_{s \beta}
\end{aligned}
$$

The magnitudes of the stator voltage and current are

$$
\begin{aligned}
& \left|v_{s}\right|=\sqrt{\left(v_{s \alpha}\right)^{2}+\left(v_{s \beta}\right)^{2}} \\
& \left|i_{s}\right|=\sqrt{\left(i_{s \alpha}\right)^{2}+\left(i_{s \beta}\right)^{2}}
\end{aligned}
$$




$$
T_{s}=\frac{1}{2 f_{s}}
$$

$r_{\mathrm{s}}, r_{\mathrm{r}}, x_{\mathrm{s}}, x_{\mathrm{r}}, f_{\mathrm{s}}$ is stator winding resistance, rotor winding resistance, stator winding reactance, rotor winding reactance and nominal frequency respectively.

$i_{r}$ is the is the space vectors of the rotor current.

$$
i_{r}=i_{r \alpha}+j i_{r \beta}
$$

$\psi_{s}, \psi_{r}$ is the is the space vectors of the stator flux and rotor flux respectively.

$$
\begin{aligned}
& \psi_{s}=\psi_{s \alpha}+j \psi_{s \beta} \\
& \psi_{r}=\psi_{r_{\alpha}}+j \psi_{r \beta}
\end{aligned}
$$

The magnitude of the stator and rotor flux:

$$
\begin{aligned}
& \left|\psi_{s}\right|=\sqrt{\left(\psi_{s \alpha}\right)^{2}+\left(\psi_{s \beta}\right)^{2}} \\
& \left|\psi_{r}\right|=\sqrt{\left(\psi_{r_{\alpha}}\right)^{2}+\left(\psi_{r_{\beta}}\right)^{2}}
\end{aligned}
$$

2. Current-flux equations:

$$
\begin{aligned}
& \psi_{s}=x_{s} i_{s}+x_{m} i_{r} \\
& \psi_{r}=x_{r} i_{r}+x_{m} i_{s}
\end{aligned}
$$

$x_{m}$ is the magnetizing reactance

3. The equation of motion:

$$
\begin{aligned}
& \frac{d \omega_{m}}{d t}=\frac{1}{T_{M}}\left(T_{e}-T_{o}\right) \\
& T_{e}=\psi_{s \alpha} i_{s \beta}-\psi_{s \beta} i_{s \alpha}
\end{aligned}
$$

$\omega_{m}, T_{M}, T e, T_{o}$ is the rotor speed, mechanical time constant, electromagnetic torque, load torque respectively.

The vector control fundamental equations allows the IM to operate like a separately excited DC machine with decoupled control of torque and flux making the IM to operate as a high performance during all operation regions (M. H. Shin et al., 2002 \& Z. V. Lakaparampil et al., 1996). Simulink implementation of IM can be shown in Figure4.

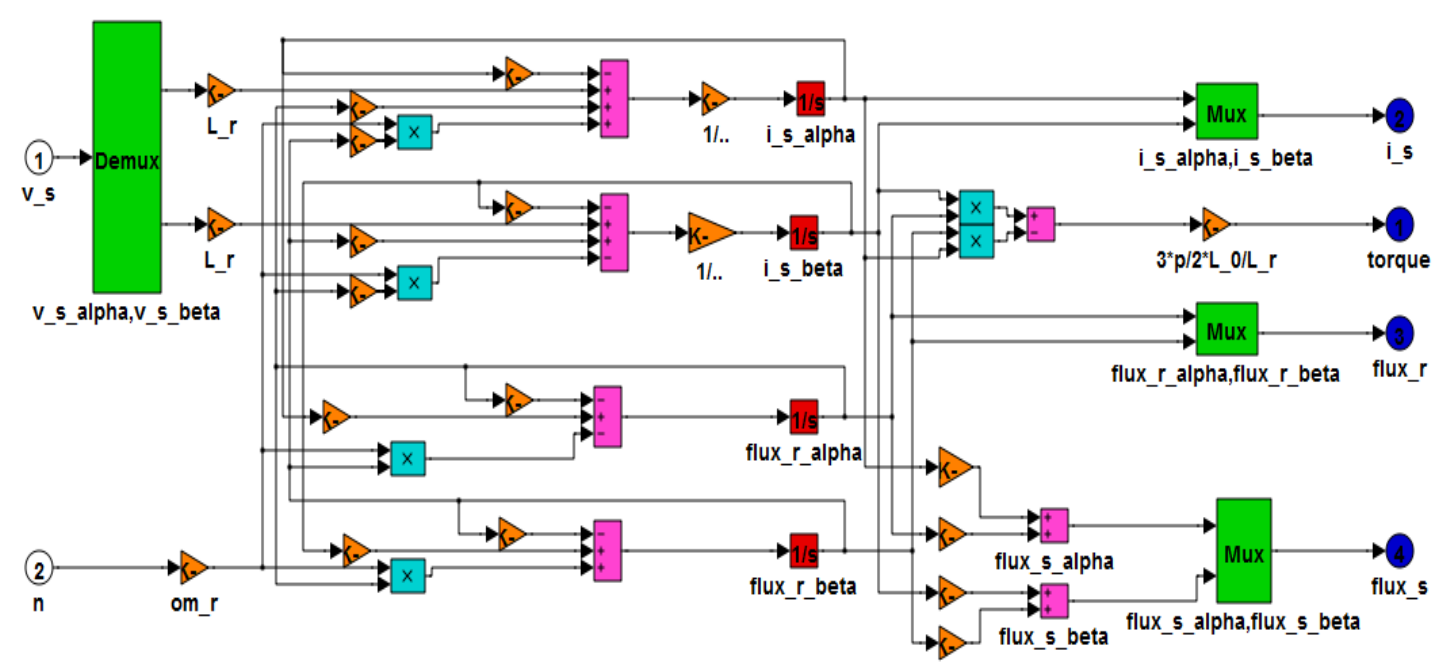

Figure 4. Simulink implementation of IM 


\section{FW Control of IM}

A stable current regulation as well as better robustness of operation can be provided during FW region and making sure that the IM is operated within a maximum performance of operation (K. Nguyen et al., 2012).

The FW principle is to allow operation of variable speed IM drives at more than rated speed as can be seen in Figure5.

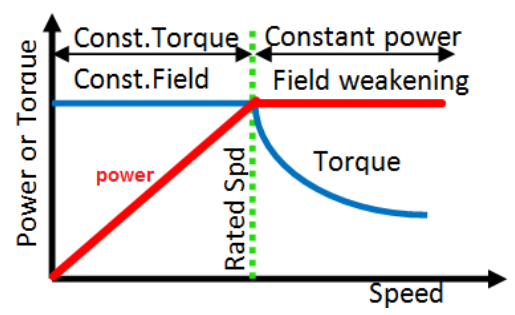

Figure 5. Typical Capability curve of Induction machine

The DC voltage supply is the main effected parameter to reduce the maximum torque production in the FW region during the operation. The stator flux magnitude in inversely proportion to rotor speed as:

$$
\psi_{s} \propto 1 / \omega_{r}
$$

In IM, the hysteresis curve can be used to measure the main flux produced. Both magnetizing inductance and magnetizing flux will be a functions of magnetizing current (A B. Ali et al., 2009).The magnetizing inductance and magnetizing current relationship is illustrated in the Figure 6.

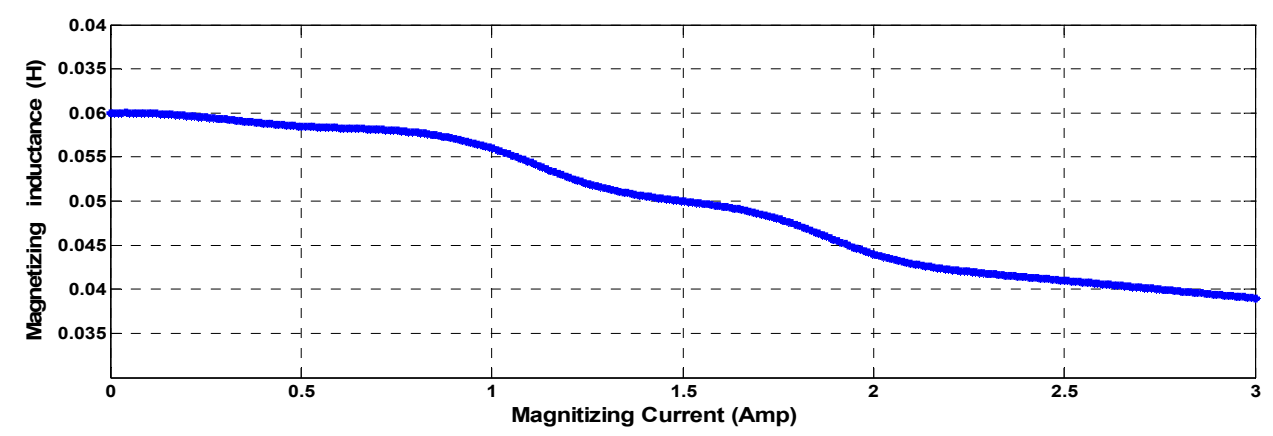

Figure 6. Variation of magnetizing inductance and current

The optimal mathematical model variation of magnetizing current and inductance will be as in (10)

$$
L_{m}=0.019 I_{m}^{3}-0.099 I_{m}^{2}+0.024 I_{m}+0.06
$$

In the FOCIM, the electromagnetic torque is expressed as:

$$
T=(1 / 3) p^{*}\left(L_{m}^{2} / L_{r}\right)\left(i_{s d} i_{s q}\right)
$$

The simulink implementation of the FW circuit can be seen in Figure7.

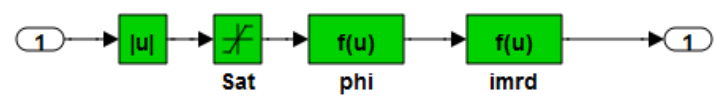

Figure 7. Simulink implementation of FW unit

\section{SVPWM Technique}

The SVPWM generates the appropriate gate drive waveform for each PWM cycle. The inverter is treated as one single unit and can combine different switching state (Bengi Tolunay, 2012].

The principle of SVM is based on the fact that there are only eight possible switching combinations for a three phase inverter to calculate inverter transistor on times. The transition from one switching state to the next 
involves only two switches in the same inverter leg, when one being switched ON, the other being switched OFF, in order to minimize the device switching loss (Z. V. Lakaparampil et al., 1996).

Figure8 illustrates the structure of a typical 3- $\varphi$ voltage source inverter. The 3- $\varphi$ voltages are represented by $V_{a}$, $V_{b}$ and $V_{c}$. The switches are represented by $s_{1}$ through $s_{6}$ and $G_{1}$ through $G_{6}$ are the gate signals.

For IM control, when an upper transistor is switched ON, i.e., when $\mathrm{G}_{1}, \mathrm{G}_{3}$ or $\mathrm{G}_{5}$ is 1 , the corresponding lower transistor is switched OFF, i.e., the corresponding $\mathrm{G}_{2}, \mathrm{G}_{4}$ or $\mathrm{G}_{6}$ is 0 .

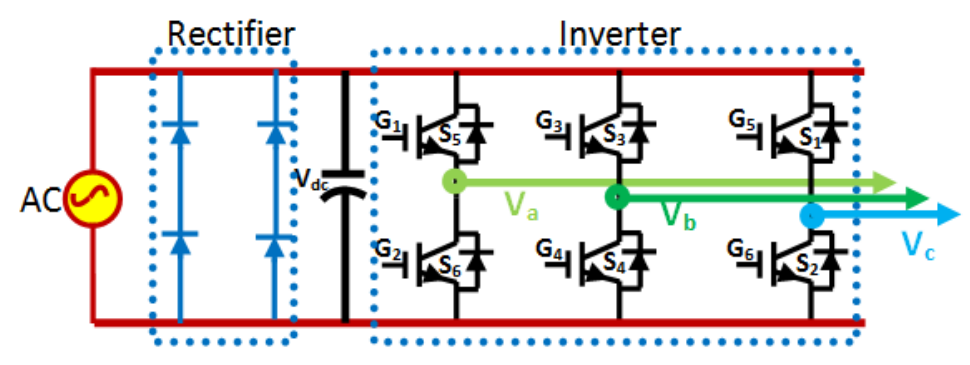

Figure 8. Inverter with the rectifier stage

The relationship between the switching variable vector $\left[\mathrm{G}_{1}, \mathrm{G}_{3}, \mathrm{G}_{5}\right]$ and the line-to-line voltage vector $\left[\mathrm{V}_{\mathrm{ab}} \mathrm{V}_{\mathrm{bc}}\right.$ $\mathrm{V}_{\text {ca }}$ ] is given by Equation(12):

$$
\left[\begin{array}{l}
V_{a b} \\
V_{b c} \\
V_{c a}
\end{array}\right]=V_{d c}\left[\begin{array}{ccc}
1 & -1 & 0 \\
0 & 1 & -1 \\
-1 & 0 & 1
\end{array}\right]\left[\begin{array}{l}
G_{1} \\
G_{3} \\
G_{5}
\end{array}\right]
$$

Equation (13) determines the phase voltage vector $\left[\mathrm{V}_{\mathrm{a}} \mathrm{V}_{\mathrm{b}} \mathrm{V}_{\mathrm{c}}\right]$, where $\mathrm{V}_{\mathrm{dc}}$ is the DC supply voltage, or the bus voltage.

$$
\left[\begin{array}{l}
V_{a} \\
V_{b} \\
V_{c}
\end{array}\right]=\frac{1}{3} V_{d c}\left[\begin{array}{ccc}
2 & -1 & -1 \\
-1 & 2 & -1 \\
-1 & -1 & 2
\end{array}\right]\left[\begin{array}{l}
G_{1} \\
G_{3} \\
G_{5}
\end{array}\right]
$$

The $V_{\max }$ is limited in the linear region to $V_{d c / 3}$. As shown in Figure9, there are eight possible combinations of $\mathrm{ON}$ and OFF patterns for the three upper power transistors that feed the three phase power inverter. Notice that the $\mathrm{ON}$ and OFF states of the lower power transistors are opposite to the upper ones. The eight combinations and the derived output line-to-line and phase voltages in terms of DC supply voltage $\mathrm{V}_{\mathrm{dc}}$, are shown in Table1.

Table 1. Switching patterns and output voltages of the inverter

\begin{tabular}{ccccccccc}
\hline $\mathrm{G}_{1}$ & $\mathrm{G}_{3}$ & $\mathrm{G}_{5}$ & $\mathrm{~V}_{\mathrm{a}}$ & $\mathrm{V}_{\mathrm{b}}$ & $\mathrm{V}_{\mathrm{c}}$ & $\mathrm{V}_{\mathrm{ab}}$ & $\mathrm{V}_{\mathrm{bc}}$ & $\mathrm{V}_{\mathrm{ca}}$ \\
\hline 0 & 0 & 0 & 0 & 0 & 0 & 0 & 0 & 0 \\
1 & 0 & 0 & $2 / 3$ & $-1 / 3$ & $-1 / 3$ & 1 & 0 & -1 \\
1 & 1 & 0 & $1 / 3$ & $1 / 3$ & $-2 / 3$ & 0 & 1 & -1 \\
0 & 1 & 0 & $-1 / 3$ & $2 / 3$ & $-1 / 3$ & -1 & 1 & 0 \\
0 & 1 & 1 & $-2 / 3$ & $1 / 3$ & $1 / 3$ & -1 & 0 & 1 \\
0 & 0 & 1 & $-1 / 3$ & $-1 / 3$ & $2 / 3$ & 0 & -1 & 1 \\
1 & 0 & 1 & $1 / 3$ & $-2 / 3$ & $1 / 3$ & 1 & -1 & 0 \\
1 & 1 & 1 & 0 & 0 & 0 & 0 & 0 & 0 \\
\hline
\end{tabular}

In the space vector PWM method, the reference voltage vector is approximated using a combination of the eight switching patterns (Zhenyu Yu \& David Figoli,1998). Figure 9 shows the space vectors denoted by $\mathrm{V}_{0}, \mathrm{~V}_{60}, \mathrm{~V}_{120}$, $\mathrm{V}_{180}, \mathrm{~V}_{240}, \mathrm{~V}_{300}$, Origin000 and Origin111. A straightforward approach of approximating the reference voltage vector is generating an average output for a small time period that equals the average of $\mathrm{V}_{0}$. Equation (14) illustrates this for time periods $T_{1}$ and $T_{2}$, during which switching patterns $\mathrm{U}_{\mathrm{x}}$ and $\mathrm{U}_{\mathrm{x} \pm 60}$ form the sector containing $\mathrm{U}_{\text {out }}$ (Khalaf salloum Gaeid, 2013). 


$$
\frac{1}{T} \int_{n T}^{(n+1) T} U_{\text {out }}=\frac{1}{T}\left(T_{1} U_{x}+T_{2} U_{x \pm 60}\right.
$$

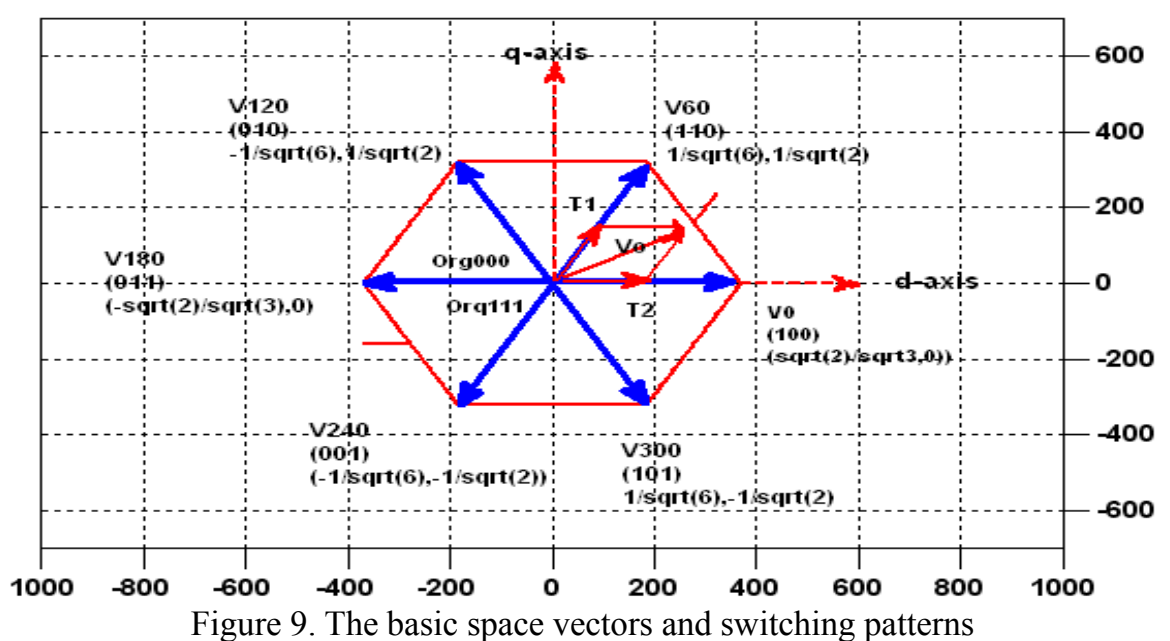

The simulink implementation of the SVM control signal can be shown in Figure10.

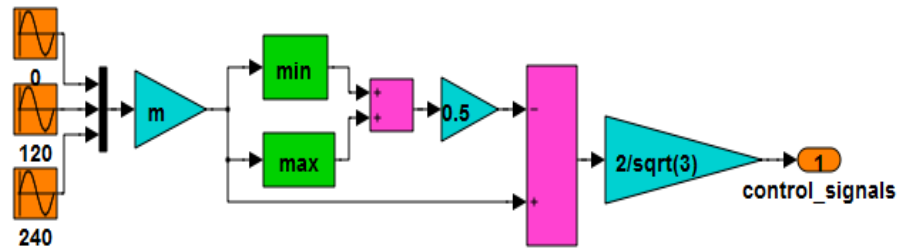

Figure 10. Space vector modulation generation

\section{Sliding Mode Observer}

The SMC is a very important strategy in the nonlinear control with uncertain systems (J. J. Slotine et al.,1991\& V.I. Utkin et al.,1999).Utilization of discontinuous function and high control gain gives powerful features to the performance specifications of the closed loop system.Figure11. Shows the main components of the SMO.

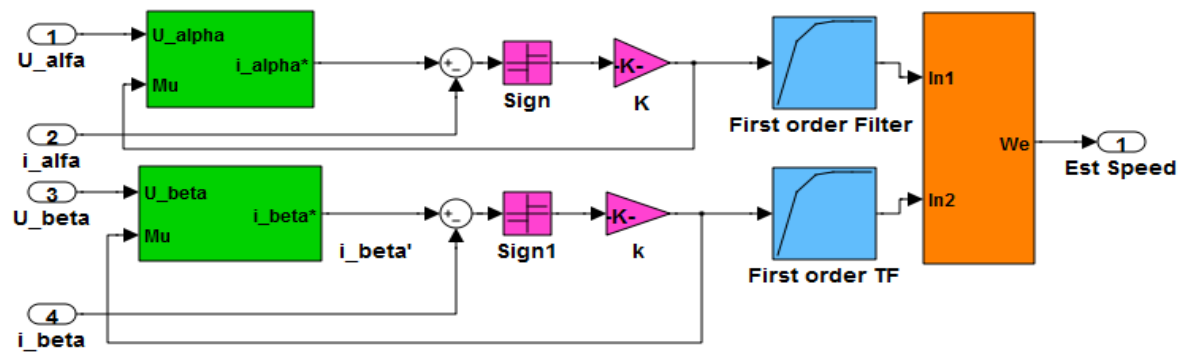

Figure 11. Simulink implementation of SMO

In the FW region, the accuracy of the speed estimation not influenced by the variation of stator resistance (A. Derdiyok, 2003).SMC is a control strategy for variable structure system (VSS), having switching logic and its considered to be the sufficient solution for the nonlinear control of IM drives at high frequency due to its disturbance elimination, strong robustness and simple implementation (Yan, Z., \& Utkin V., 2002).

In SMC a sliding surface (slice) on the main system trajectory is reached by proper control law design. Another parameter is the sliding phase which is a phase of slides toward the stability point.

The error between the reference current parameter and estimated parameter moved towards a sliding surface. The sliding surface (slices) is defined according to this error and its rate of change is a variables. The alpha and beta components of the voltage and current are estimated using the DC-link voltage and the inverter transistors 
positions. These components will be the control input to the this system as in Figure11.

The tracking error will be the input to sign unit to force it to move to the predefined sliding surface. The sign properties as

$$
\operatorname{sign}(s)=\left\{\begin{array}{lll}
1 & \text { for } & s>0 \\
0 & \text { for } & s=0 \\
-1 & \text { for } & s<0
\end{array}\right.
$$

It's clear from Figure11, the mechanical speed is replaced by the estimated one, and an additional variable (mu in the green block) is introduced for tuning the flux and current estimators (S.Tami et al., 1987). The estimated rotor flux vector is:

$$
T_{N} \frac{d \widehat{\psi}_{r}}{d t}=-\left(\frac{r_{r}}{x_{r}}+\widehat{\mu}\right) \widehat{\psi}_{r}+\frac{x_{m} r_{r}}{x_{r}}+j \omega_{m} \widehat{\psi}_{r}
$$

The estimated speed can be calculated by:

$$
\widehat{\omega}_{m}=k \operatorname{signs}_{\omega}
$$

where: $K$-positive constant.

Speed switching function is:

$$
s_{\omega}=\left(\hat{i}_{s \beta}-i_{s \beta}\right) \widehat{\psi}_{r \alpha}-\left(\hat{i}_{s \alpha}-i_{s \alpha}\right) \widehat{\psi}_{r \beta}
$$

The high frequency speed is undesirable and it must be filtered through a low pass filter (LPF):

$$
\omega_{m}=\widehat{\omega}_{m} \frac{1}{0.3 T_{s} s+1}
$$

$T_{s}$ is the setting time of the system

The better filter time constant is found during the experiment to be $0.3 T_{s}$ as can be shown in Figure 12 .

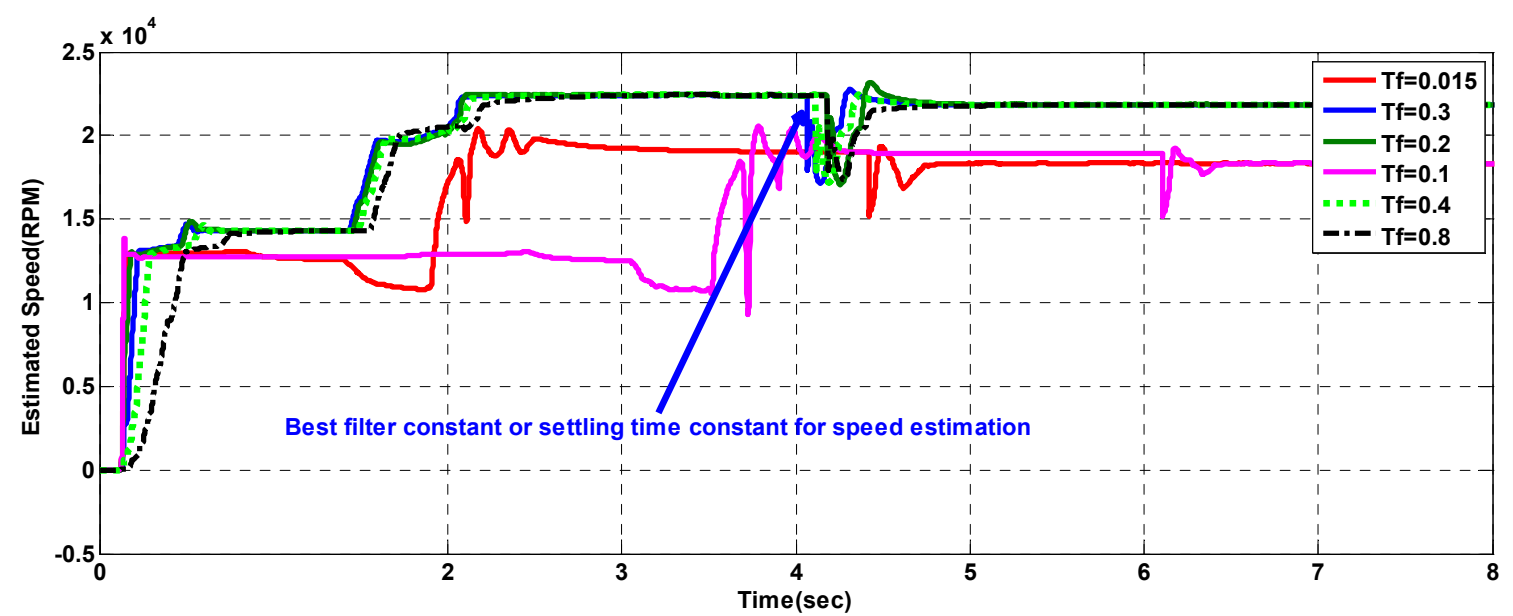

Figure 12. Filter time constant selection

From Figure12. It can be seen, that the filter time constant between three to four time constant gives the smallest oscillation level. This will yield a fast speed response and the oscillation can be reduced. The closed loops control with PI controllers is required to obtain good performance without fine tuning. The proposed algorithm implemented with Simulink/Matlab as shown in Figure 13. 


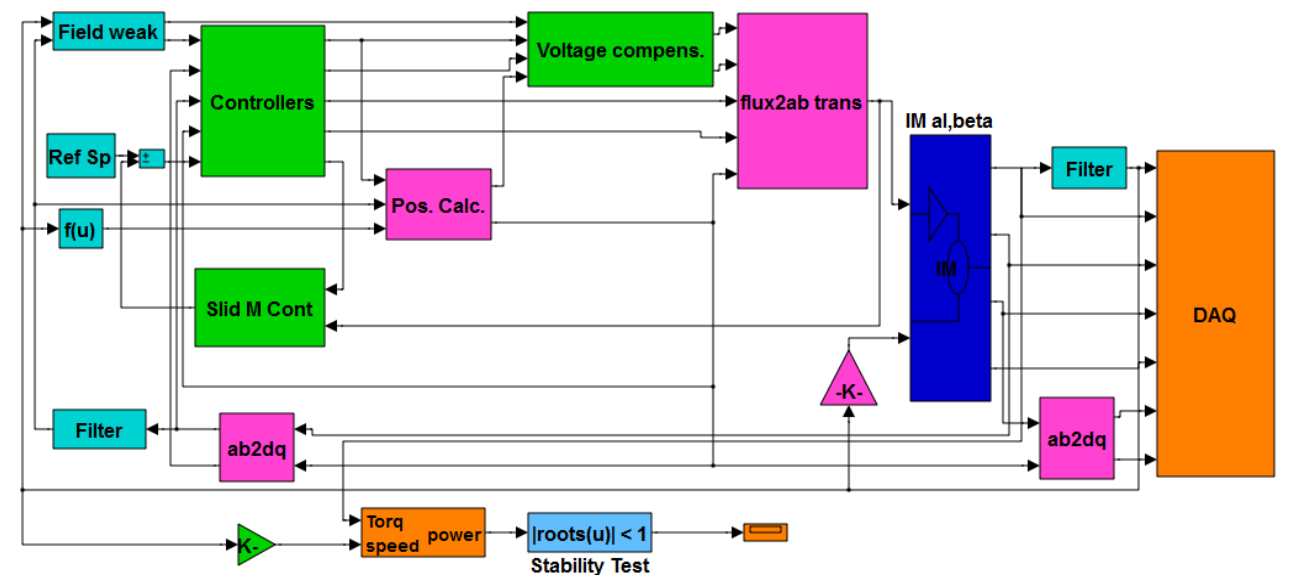

Figure 13. Simulink implementation of the proposed algorithm

\section{Simulation Results}

The IM used for the simulation is a $1 \mathrm{~kW}$ having a parameters as given in Table 2 .

Table 2. IM parameters

\begin{tabular}{lll}
\hline Parameter & Value & Unit \\
\hline Stator resistance & 0.55 & $\Omega$ \\
Rotor resistance & 0.375 & $\Omega$ \\
Stator inductance & 0.112 & $\mathrm{H}$ \\
Rotor inductance & 0.105 & $\mathrm{H}$ \\
Mutual inductance & 0.103 & $\mathrm{H}$ \\
\hline
\end{tabular}

In the simulation, the IM starts from a standstill state with reference speed 1000 RPM between [0-1.6]sec and changed to 2500 RPM after that up to 4 sec to become 2000 RPM.

The reference speed of the proposed algorithm is shown in Figure14.

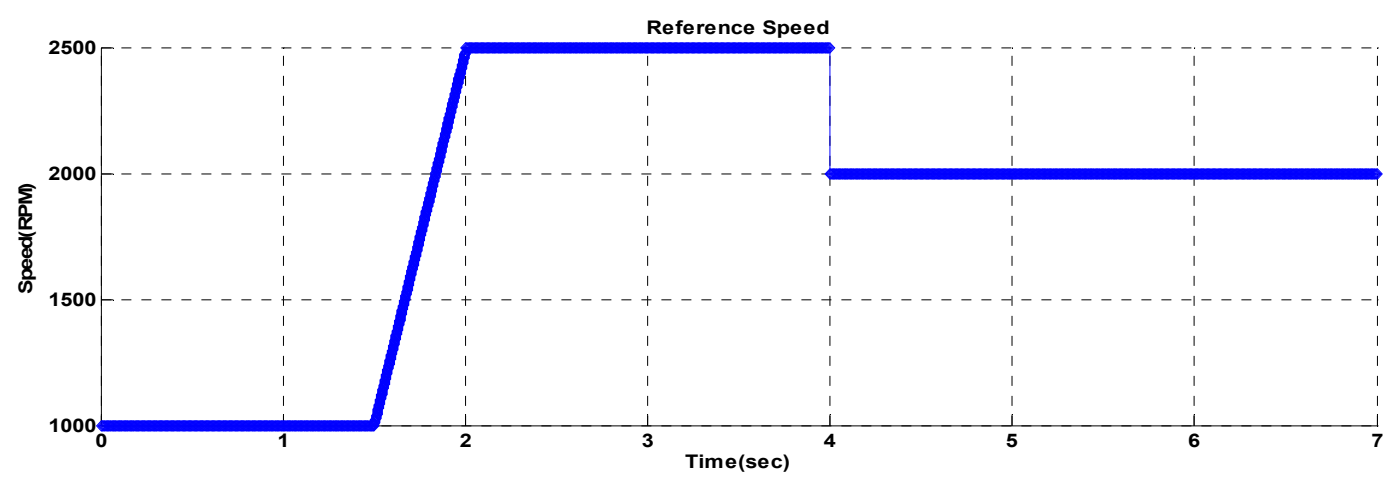

Figure 14. Reference speed of the proposed algorithm

The actual speed response of the IM is shown in Figure15. 


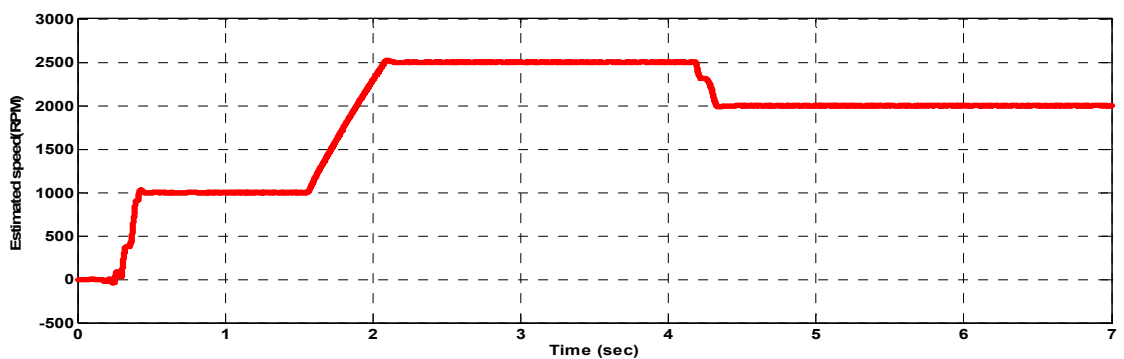

Figure 15. Output speed response variation

The speed of 1000RPM , 2000RPM and 2500 RPM is achieved in $0.4 \mathrm{sec}$ time delay and enters to FW region.

The FW operation of the IM drives a to vary the rotor flux reference in inversely proportion to rotor speed as can seen in Figure16,this is according to the reference speed variation.

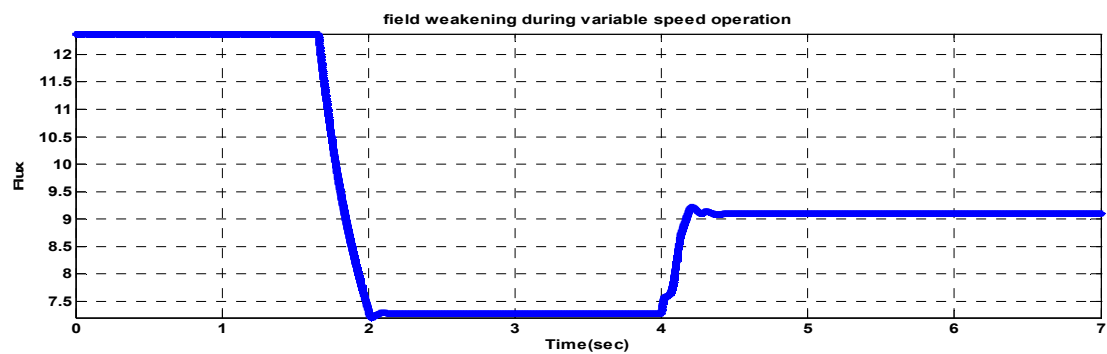

Figure 16. Variation of magnetizing inductance and current

The reference and actual flux during the FW region is measured at a constant speed of operation (2000 RPM) as shown in Figure17.

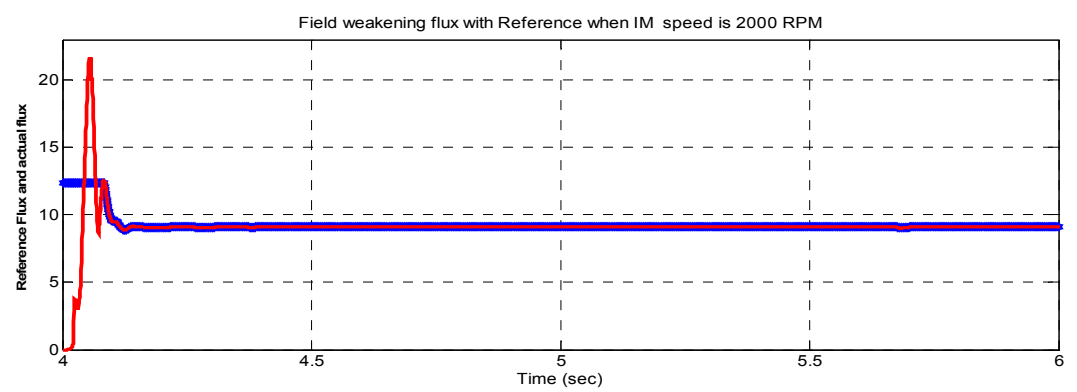

Figure 17. Flux with its reference in the FW region with 2000 RPM

Figure 8 present the transient response of torque without LPF as the rotor speed changes from 0 to 1000 RPM, (1000 to 2500) RPM and [2500-2000]RPM. The motor torque has a 1N.m value in the first region, 2 N.m in the second region of operation and maintains the rated value of $1.8 \mathrm{~N}$. m. in the third region.

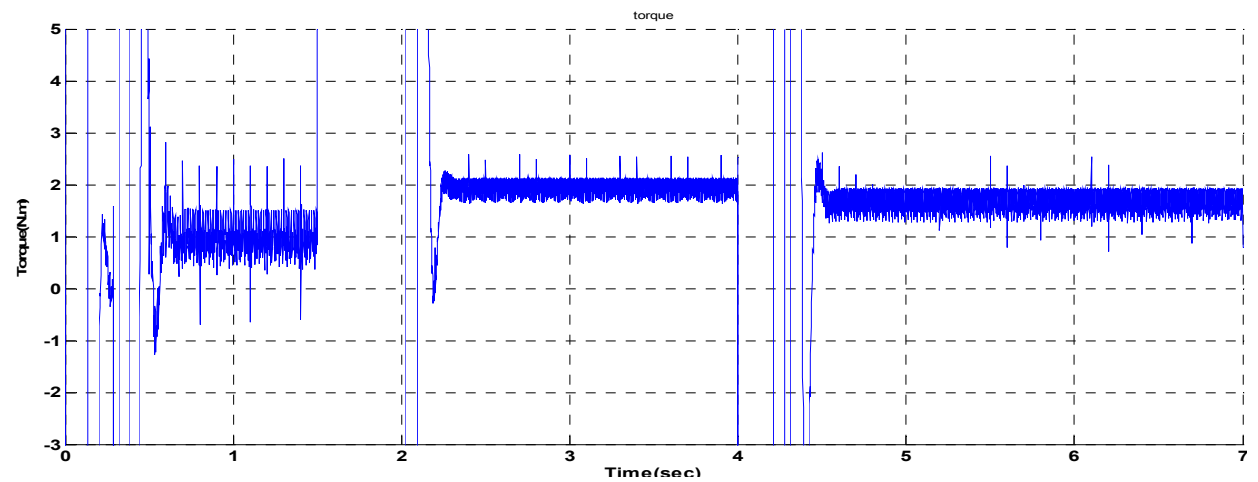

Figure 18. IM torque with the LPS design and optimal flux usage 
Figure19 present the transient response of torque with LPF and optimal flux under same above condition The motor torque has a $0.8 \mathrm{~N} . \mathrm{m}$ value in the first region, $1.9 \mathrm{~N} . \mathrm{m}$ in the second region of operation and maintains the rated value of $1.5 \mathrm{~N}$. m. in the third region.

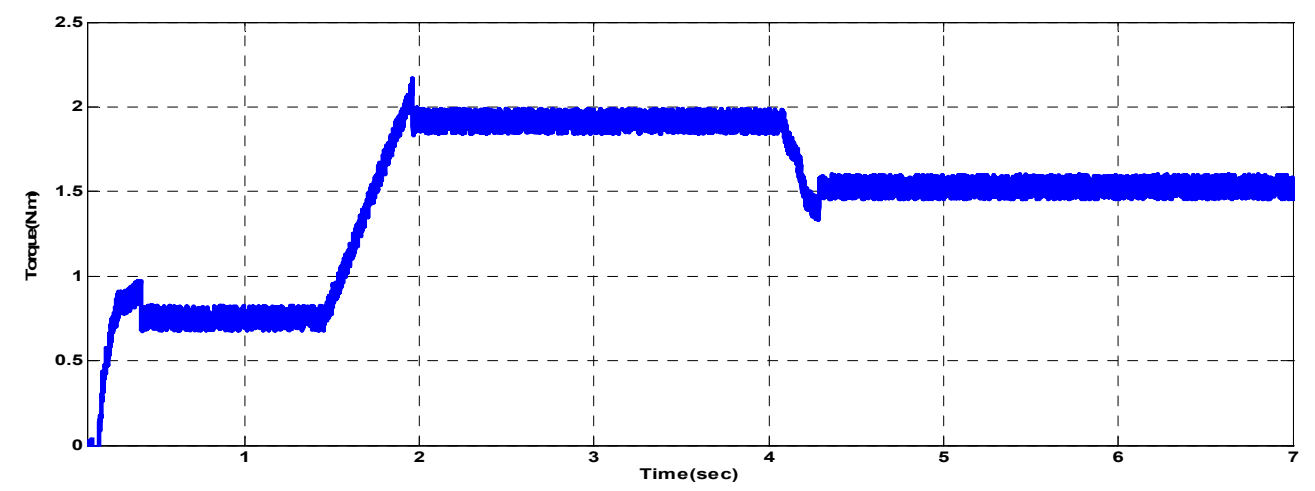

Figure 19. Torque of IM under LPF and optimal flux constrains

Figure 20 shows the variation of rotor flux and stator flux for all rotor speed variations.
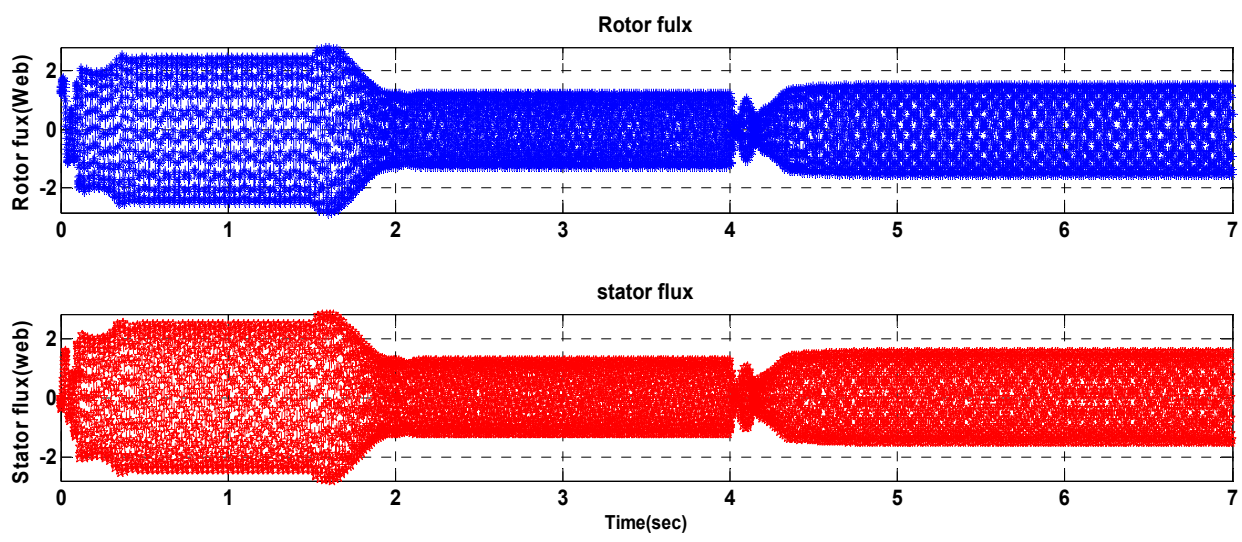

Figure 20. IM rotor flux (above) and stator flux(below)

Optimal rotor flux can be designed according to the following Equation(Khalaf Salloum Gaeid and Hew Wooi Ping, 2011)

$$
\phi_{\text {optimal }}=\left|T_{e} * \sqrt{R_{r} /(1.5 * P)}\right|
$$

Figure 21 shows the optimal rotor flux variation during the FW region.

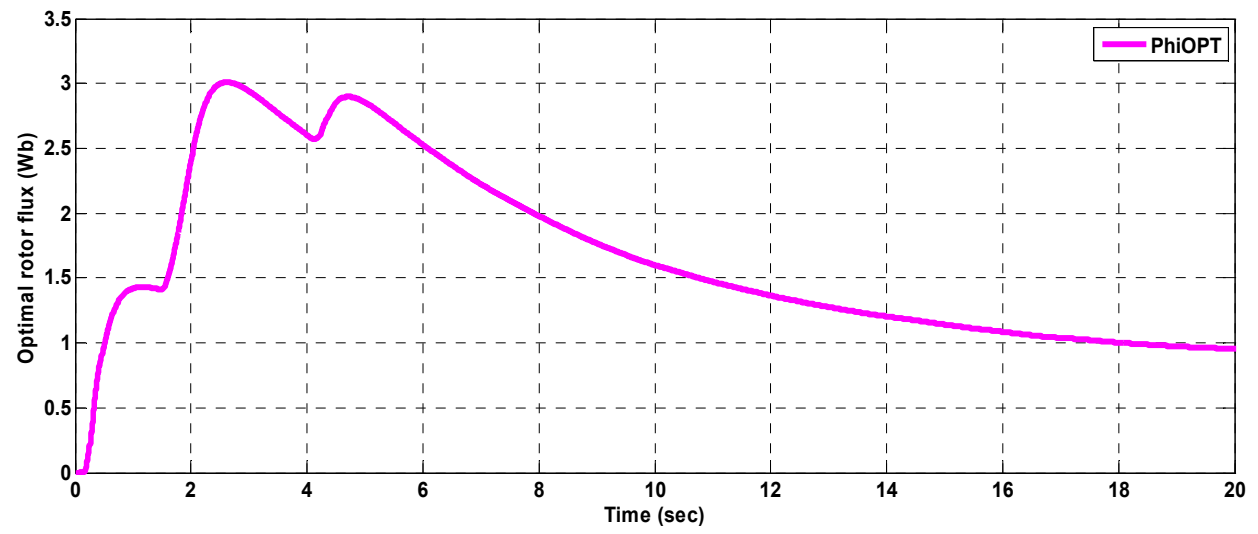

Figure 21. IM optimal flux measurement in all regions of operation

Variations of stator current ias and ißs prepared for inverter fed IM during FW region are presented in Figure 22. 

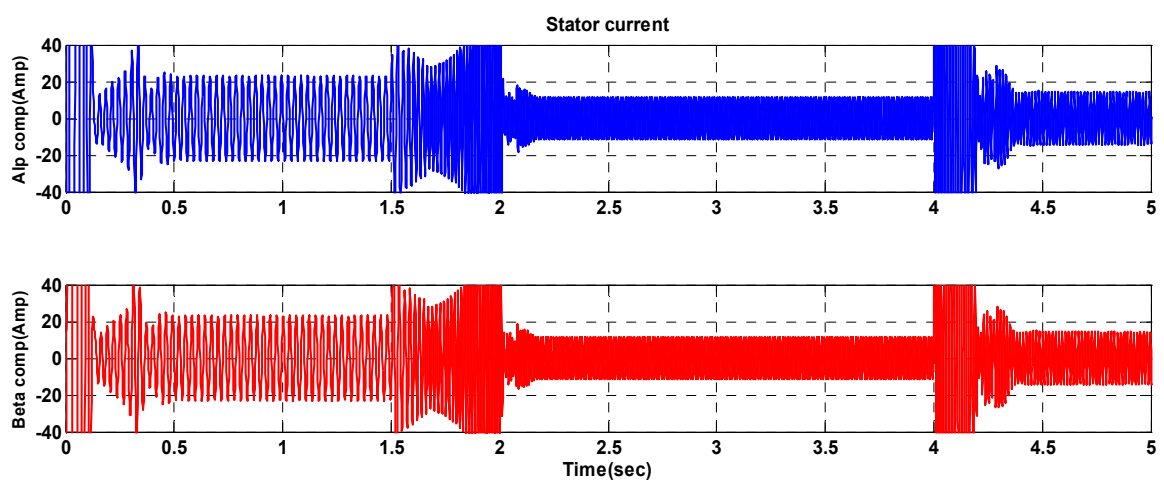

Figure 22. IM stator current components, i $\alpha$ s (above) and i $\beta$ s (below)

\section{Conclusions}

In this paper, a SMO in FW region for SVPWM fed IM is developed. The performance of the developed algorithm has been illustrated in the FW region and the speed and torque responses are analyzed.

In this method, the variable speed transition and FW region is smooth in operation with the LPF, depending upon the voltage and current limits, better accuracy in all ranges of speed control has been obtained through the proposed SMO scheme.

SMO has the ability to do accurate speed estimation for any operating point in the FW region.

\section{Acknowledgements}

I would like to express my sincere gratitude to Prof. Hew Wooi Ping from University of Malaya/Malaysia and Prof .M. Nasir Uddin from Lakehead University/Canada.

\section{References}

Ali, A. B., Khedher, A., Mimouni, M. F., \& Dhifaoui, R. (2009). Torque maximization and sensorless control of induction motor in a flux weakening region. IJSTA, 3(1), 972-985.

Arafa, S., Mohamed, M. S., Zaky, A. S., Zein, E. D., \& Hussain, A. Y. (2011). Comparative Study of Sensorless Control Methods of PMSM Drives. Innovative Systems Design and Engineering, 2(5), 44-66.

Basha, C. K., \& Suryakalavathi, M. (2013). Estimation of Rotor Flux using Neural Network Observer in Speed Sensorless Induction Motor Drive. International Journal of Computer Applications, (1- 6), 79.

Bengi, T. (2012). Space Vector Pulse Width Modulation for Three-Level Converters - a Lab VIEW Implementation. Thesis in Electrical Engineering, Uppsala University.

Boyu, Y., Kang, L. Y., Jiang, K., \& Lin, Y. J. (2013). A Two-stage Kalman Filter for Sensorless Direct Torque Controlled PM Synchronous Motor Drive. Mathematical Problems in Engineering, Article ID 768736, pp.1-12.

Casadei, D., Serra, G., Tani, A., \& Zarri, L. (2006). A robust method for field weakening operation of induction motor drive with maximum torque capability, Conf. Rec. IEEE IAS, 111-117.

Derdiyok, A. (2003). A novel speed estimation algorithm for induction machines, Electrical Power System Research, (64), 73-80. http://dx.doi.org/10.1016/S0378-7796(02)00155-4

Feng, Y., Zhou, M. H., \& Yu, X. H. (2012). Sliding-Mode Observer Based Flux Estimation of Induction Motors. Intelligent Robotics and Applications Lecture Notes in Computer Science, 7507, 530-539.

Gaeid, K. S., Ping, H. W., Khalid, M., \& Masaoud, A. (2012).Sensor and Sensorless Fault Tolerant Control for Induction Motors Using a Wavelet Index. Sensors, 12(4), 4031-4050. http://dx.doi.org/10.3390/s120404031

Grzegorz, T., \& Teresa, O. K. (2013). Sliding Mode Speed Observer for the Induction Motor Drive with Different Sign Function Approximation Forms and Gain Adaptation. Przegląd Elektrotechniczny, 89(1a), $1-6$.

Khalaf, S. G. (2013). Space vector Modulation for V/f Induction Motor Control, Wulfenia, 20(3), 166-178.

Khalaf, S. G., \& Hew, W. P. (2011). Wavelet Fault Diagnosis of Induction Motor. MATLAB for Engineers Applications in Control, Electrical Engineering, IT and Robotics chapter, (14), 341-364. 
Khalaf, S. G., \& Hew, W. P. (2012). Fault Tolerant Control of Induction Motor through Observer Techniques II. Scientific Research and Essays, 7(6), 679-692.

Kusuma, G., Prashanth, Y. V., Mahesh, P., Sumith, Y., \& Kiran, P. S. (2013). Simulation of DTC IM Based on PI\& Artificial Neural Network Technique. International Journal of Advanced Research in Electrical, Electronics and Instrumentation Engineering, 2(7), 3340-3348.

Lakaparampil, Z. V., Fathima, K. A., \& Ranganathan, V. T. (1996). Design modeling simulation and implementation of vector controlled induction motor drive. in Proc. PEDES, 2, 862-868.

Lin, P. Y., \& Lai, Y. S. (2011). Novel voltage trajectory control for field weakening operation of induction motor drives. IEEE Trans. Ind. Appl., 47(1), 122-127. http://dx.doi.org/10.1109/TIA.2010.2091092

Mateusz, D., Teresa, O. K., \& Grzegorz, T. (2013). Sensorless Traction Drive System with Sliding Mode and MRASCC Estimators using Direct Torque Control. Automatika, 54(3), 329-336.

Nguyen, K., Thact, T., Orlowska, K., \& Tarchala, G. (2012). Comparative analysis of the chosen field-weakening methods for the Direct Rotor Flux Oriented Control drive system. Archives of electrical engineering, 61(4), 443-454.

Saghafinia, A., Hew, W. P., \& Mohammad, N. U. (2013). Sensored Field Oriented Control of a Robust Induction Motor Drive Using a Novel Boundary Layer Fuzzy Controller. Sensors, 13(12), 17025-17056. http://dx.doi.org/10.3390/s131217025

Shin, M. H., Hyun, D. S., \& Cho, S. B. (2002). Maximum torque control of stator flux oriented induction machine drive in the field weakening region. IEEE Trans. Ind. Appl., 38(1), 117-122. http://dx.doi.org/10.1109/28.980365

Slotine, J. J., \& Li, W. (1991). Applied nonlinear control, Prentice Hall Ed.

Sobha, C. B. (2007). Sliding Mode Vector Control of Three Phase Induction. Master thesis of Technology in Power Control and Drives, National Institute of Technology, Rourkela Orissa.

Tami, S., Sugimoto, H., \& Masao, Y. (1987). Speed sensorless vector control of induction motor with model reference adaptive system. in conf. IEEE/IAS. Annu.Meeting, 189-195.

Utkin, V. I., Guldner, J., \& Shi, J. (1999). Sliding mode in control in electromechanical systems, Taylor \& Francis Ed.

Vas, P. (1992). Electrical Machines and Drives: A Space vector Theory Approach. Oxford: Clarendon Press.

Venkatesh, G., VijayaBhaskar, S., \& Reddy, B. M. (2013). Efficient Speed Estimation of an Induction Motor Drive Using Sliding Mode Observer Algorithm. International Journal of Engineering Research \& Technology, 2(10), 2746-2750.

Wang, D. F., Hu, Z. F., Zhu, C., Zhou, C. W., \& Xie, Y. J. (2013). Stator Flux Observer for Induction Motor Based on Tracking Differentiator. Mathematical Problems in Engineering, Article ID 927582, 1- 8.

Yan, Z., \& Utkin, V. (2002). Sliding mode observers for electric machines-an overview. 28th IECON Annual Conf. of the IEEE Ind. Electrical Society, 1842-1847.

Yan, Z., Jin, C., \& Utkin, V. (2000). Sensorless sliding-mode control of induction Motors, IEEE Trans. Industrial Electronics, 47(6), 1286-1297. http://dx.doi.org/10.1109/41.887957

Yu, Z. Y., \& David, F. (1998). AC Induction Motor Control Using Constant V/Hz Principle and Space Vector PWM Technique with TMS320C240. Application Report: SPRA284A, Texas Instrument.

\section{Copyrights}

Copyright for this article is retained by the author(s), with first publication rights granted to the journal.

This is an open-access article distributed under the terms and conditions of the Creative Commons Attribution license (http://creativecommons.org/licenses/by/3.0/). 